\title{
Automated Detection and Notification of Pothole to Aid Driver
}

\author{
Bhagyashree Ghodake \\ Computer Engineering \\ JSPM's, BSIOTR, Wagholi, Pune, \\ India
}

\author{
Aparna Korade \\ Computer Engineering \\ JSPM's, BSIOTR, Wagholi, Pune, India
}

\author{
Ankita Magar \\ Computer Engineering \\ JSPM's, BSIOTR, Wagholi, Pune, \\ India
}

\author{
Kavita Nagargoje \\ Computer Engineering \\ JSPM's, BSIOTR, Wagholi, Pune, \\ India
}

\author{
Megha Jadhav \\ Computer Engineering \\ JSPM's, BSIOTR, Wagholi, Pune, India
}

\begin{abstract}
The majority of countries are in the Development race. India is in the same race, as well. Road transport is contributing the lion's share in India's Growth. Road transportation is mainly transportation nework in India among the three transport systems. This is the reason behind increased vehicle numbers in recent years. Accidents also increased with the number of cars. Path condition is the principal cause behind this incident. So maintaining the roads is important to save lives. The proposed device would track the condition of the road and identify the potholes. The identified information about the potholes will be given to the driver and also to the government
\end{abstract}

\section{Keywords}

Potholes, Ultrasonic Sensor, Wireless Sensor Network, GPS location, Android Application.

\section{INTRODUCTION}

Roads India's Roads are dominant mode of transportation. Many of the people use road for their day-- transport. Roads carry nearly 85 per cent of passenger traffic in the region. Improved even along with the car collisions. A poor road condition, potholes on the lane, is a big reason behind this[1][2]. Because of these potholes about 1 people are dying every year. Therefore it is important to collect the road condition information and provide the same to the government so that the authorities can take preventive action. So we're trying to enforce a small program by counting the potholes on the road, which will control the road conditions. The proposed system is divided into three units [3][4].

\section{LITURATURE SURVEY}

"A research of pavement potholes detection depends on threedimensional projection transformation" this paper was published by Jianfang,Q. Hanxing, Z.Wei,H. Youquan in 2016. According to this paper the system used image processing for detection of potholes. Depending on the analysis of the images of road, potholes were detected by this system[5].

"Pothole system based on Support Vector Machine" this paper was published by J. Lin and Y. Liu in 2015. According to this paper a system was developed which used support vectior machine to detect potholes [6].

"Detection of potholes using the Microsoft Kinect sensor" this paper was published in 2017 which states that potholes will be detected by using a kinetic sensors. These sensors are placed on the both side of roads which will detect the potholes. And whenever the car passes from the road information will be provided to the car driver[7][8].

\section{SYSTEM ARCHITECTURE}

The proposed framework classifies the sensor subsystem, the data processing subsystem, the logging and monitoring framework and the control subsystem into four subsystems. The vehicle is started by the control subsystem and it controls all of our hardware components. The sensors and module for data processing to start its service are used. The data processing module will look at the monitoring and logging subsystem information from the sensors and the data from the output pothole. On the android mobile device, the logging and reporting subsystem will store the pothole locations on a network server. Our system mainly consists of four modules, a mobile application module, a server module, a microcontroller module and a sensing module.

\subsection{Mobile Application Module:}

User has two choices if the "login" option is given while he is already enrolled. And the user is new to the program then the option to "register here" is given.

After successful login, user will collect the pothole warning from the device for his safe journey.

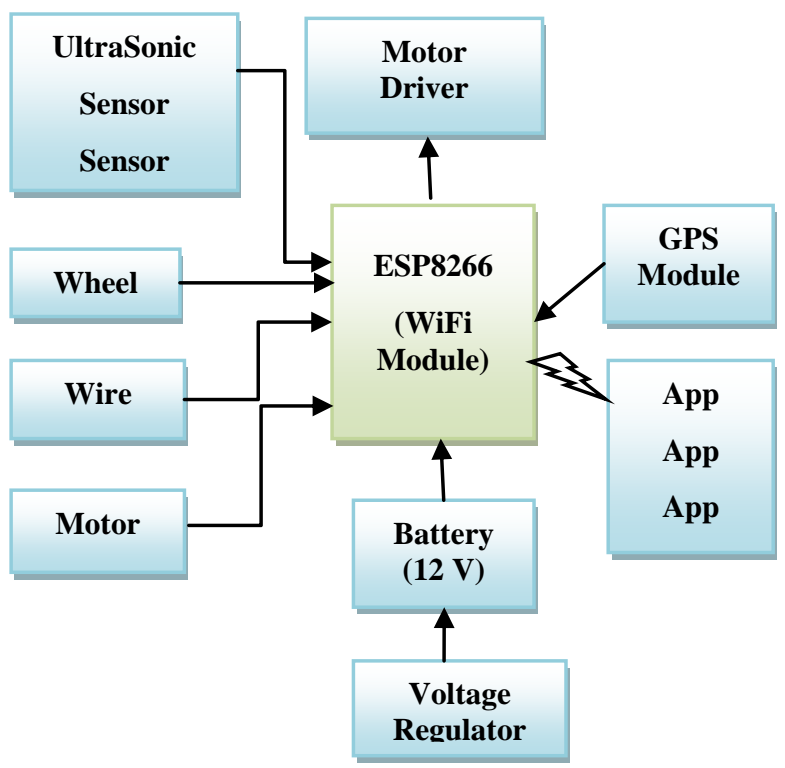

Fig 1. System Architecture 


\subsection{Server Module:}

This is the machine backend. The server module is nothing but machine database. It's an intermediate layer between module sensing and device application. Its purpose is to store the sensor's updated information and provide it to the user requested whenever appropriate. This module can also be periodically modified for details concerning the potholes. The system being proposed uses cloud to store the information. Program uses the 000webhost cloud for data storage [9][10]

\subsection{Microcontroller Module:}

The Module is responsible for coordinating the hardware and server. It collect the information collected from sensor, compare it with threashold value. If pothole is detected then server stores information. This information will include count of pothole, pothole position with longitude and latitude, and pothole detection time [11][12].

\subsection{Sensing Module:}

Consists of an ultrasonic sensor (HC-SR04). Through the assistance of an ultrasonic sensor, the distances between the car's physical body and the ground surface are measured. A threshold value is set such that the weight of the transport vehicle is dependent on ground clearance. To detect pothole or hump the measured distance (depth parameter) is compared to the threshold value. If the estimated distance is larger than the threshold value, then it is classified as a pothole, and if the measured distance is less, then it is classified as a hump [13][14].

\section{SOFTWARE REQUIREMENT SPECIFICATION}

The end user is supplied with the Mobile Device. Thus, the android studio is used to build the program. Java technology is used in computer programming. The database is stored using Mysql.

\section{MATHEMATICAL MODEL}

System $S=\{U, R, D, S, F\}$

User Module:

Set $\mathrm{U}=\mathrm{u} 1, \mathrm{u} 2, \mathrm{u} 3, \mathrm{u} 4$

- $\quad \mathrm{u} 1=$ Systems available for android use.

- $\quad \mathrm{u} 2=$ Required hardware resources

- $\quad \mathrm{u} 3=$ Execution Detection pothole.

- $\quad$ The product of $\mathrm{u} 4=$ analysis by map.

Set R = R1, R2, R3, R4

- $\mathrm{R} 1=$ get registered users.

- $\quad \mathrm{R} 2=$ allow Live Services users.

- $\quad \mathrm{R} 3=$ test the path hole for road condition.

- $\quad \mathrm{R} 4=$ Distribute implementing money.

Android Module:

Set $D=d 1, d 2, d 3, d 4, d 5$

- $\quad \mathrm{d} 1=$ The place to execute reads.

- $\quad \mathrm{d} 2=$ Full pothole research

- $\quad \mathrm{d} 3=$ Hardware and Computer resource sharing.

- $\quad \mathrm{d} 4=$ Workout.
- $\mathrm{d} 5=$ Open.

$\mathrm{S}=$ Success state The sensors will detect the values and send them to the application for users.

$\mathrm{F}=$ Failure Condition If the controller fails then the whole system fails.

\section{RESULT}

Following are the some screen shots of application which gives idea about how it is working exactly. Figure 2 shows home page of application. This result also shows log of location details as shown in figure 3. Pothole count is also calculated as shown in figure 4 . To perform all this activity hardware setup is required as shown in figure 5 .

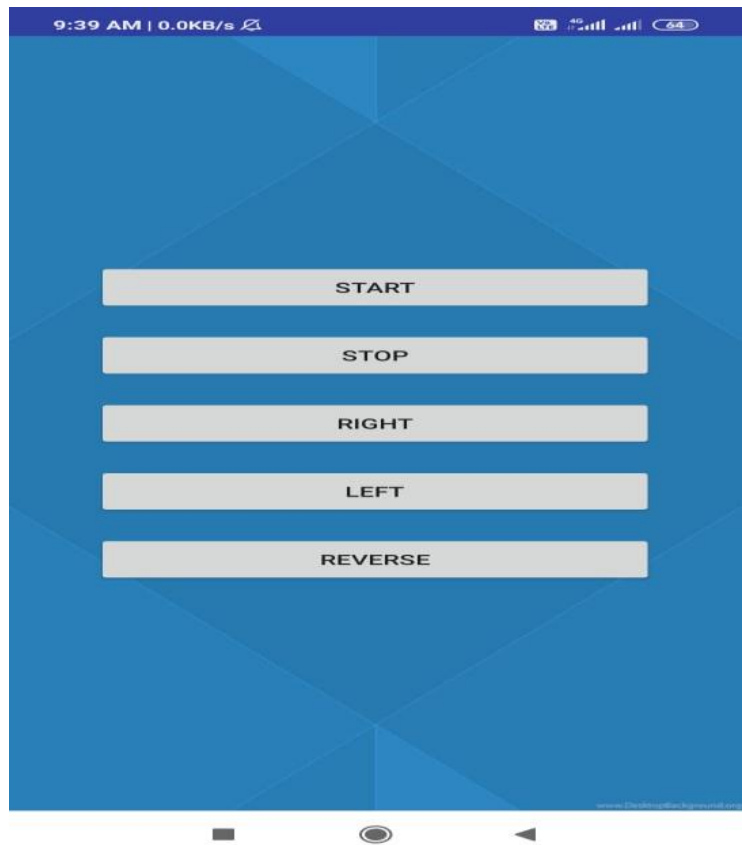

Fig 2. Android application Robot moving page

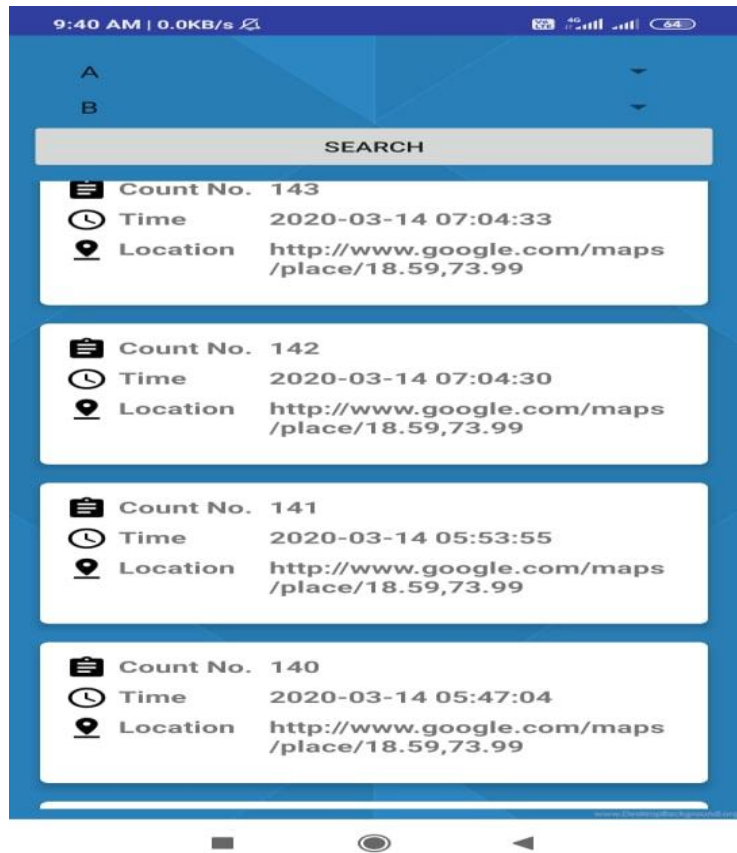

Fig 3. Android application pothole location details 


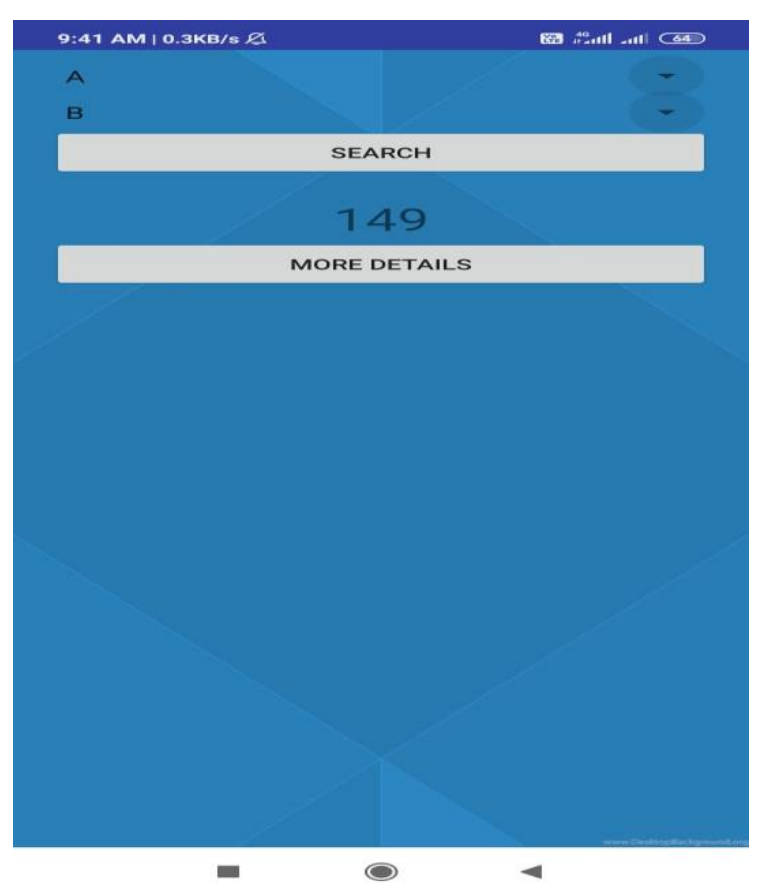

Fig 4. Android application pothole count

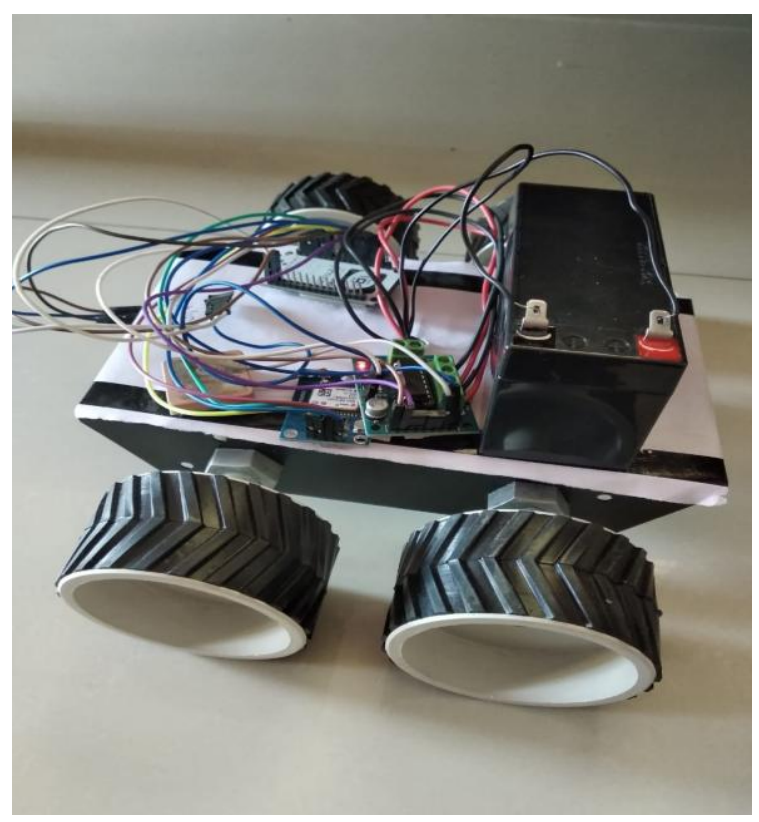

Fig 5. Hardware robot setup

\section{CONCLUSION}

The proposed device essentially serves the purpose of automatically detecting the potholes and transmitting the information about it to the smartphone apps and using GPS it can view potholes on the Google map and it is beneficial to drivers as drivers can see the potholes on the road before driving. Government officials can also use the information for road maintenance [15].

\section{REFERENCES}

[1] I. Moazzam, K. Kamal, S. Mathavan, S. Usman, and M. Rahman, Metrology and visualization of potholes using the microsoftKinect sensor, in Proc. 16th Int. IEEE Conf. Intell. Transp. Syst., Oct. 2013, pp. 12841291.
[2] S. S. Rode, S. Vijay, P. Goyal, P. Kulkarni, and K. Arya, Pothole detection and warning system: Infrastructure support and system design, in Proc. Int. Conf. Electron. Computer. Technol., Feb. 2009, pp. 286290.

[3] R. Sundar, S. Hebbar, and V. Golla, Implementing intelligent traffic control system for congestion control, ambulance clearance, and stolen vehicle detection, IEEE Sensors J., vol. 15, no. 2, pp. 11091113, Feb. 2015.

[4] SamyakKathane, VaibhavKambli, Tanil Patel and RohanKapadia, Real Time Potholes Detection and Vehicle Accident Detection and Reporting System and Anti-theft (Wireless), IJETT, Vol. 21, No. 4, March 2015.

[5] H. Youquan, W. Jian, Q. Hanxing, Z. Wei, and X. Jianfang, A research of pavement potholes detection based on three-dimensional projection transformation, in Proc. 4th Int. Congr. Image Signal Process (CISP), Oct. 2011, pp. 18051808.

[6] J. Lin and Y. Liu, Potholes detection based on SVM in the pavement distress image, in Proc. 9th Int. Symp. Distrib.Comput. Appl. Bus. Eng. Sci., Aug. 2010, pp. 544547.

[7] Taehyeong Kim, Seung-Ki Ryu, A Guideline for Pothole Classification, International Journal of Enginering and Technology (IJET), Vol. 4, No. 10, October 2014.

[8] GunjanChugh, DivyaBansal and SanjeevSofat, Road Condition De-tection Using Smartphone Sensor: A Survey, International Journal of Electronic and Electrical Engineering, Vol. 7, No. 6, 2014.

[9] S. S. Rode, S. Vijay, P. Goyal, P. Kulkarni, and K. Arya, Pothole detection and warning system: Infrastructure support and system design, in Proc. Int.Conf. Electron. computer. Technol., Feb. 2009.

[10] H. Youquan, W. Jian, Q. Hanxing, Z. Wei, and X. Jianfang, A research of pave-ment potholes detection based on three-dimensional projection transformation, in Proc. 4th Int. Congr. Image Signal Process.Oct. 2011, pp. 18051808.40

[11] Mednis, Artis, et al. Real time pothole detection using android Smart phones with accelerometers. Distributed Computing in Sensor Systems and Workshops (DCOSS), 2011 International Conference on. IEEE, 2011.

[12] Megha Jadhav, Dr. Yogeshkumar Sharma, Dr. G. M. Bhandari, Forged Multinational Currency Identification and Detection System using Deep Learning Algorithm, International Journal of Computer Applications (0975 8887) Volume 177 - No. 44, March 2020.

[13] De Silva, Girisha Det al. Automated Pothole Detection System. International Conference on Advances in ICT for Emerging Regions, Colombo, Sri Lanka. 2013

[14] Chang, K. T.J. R. Chang, and J. K. Liu. Detection of pavement distresses using 3D laser scanning technology. Computing in Civil Engineering (2005). 2011

[15] Buza, Emir, Samir Omanovic, and Alvin Huseinovic. Pothole detection with image processing and spectral clustering Proceedings of the 2ndInternational Conference on Information Technology and Computer Networks. 2013. 